All letters are subject to editing and may be shortened. Letters should be sent to the BJGP office by e-mail in the first instance, addressed to

journal@rcgp.org.uk (please include your postal address). Alternatively, they may be sent by post as an MS Word or plain text version on CD or DVD. We regret that we cannot notify authors regarding publication. Letters not published in the Journal may be posted online on our Discussion Forum. For instructions please visit: http://www.rcgp.org.uk/bjgp-discuss

\section{Practice-based research}

We have followed with interest the thread of correspondence initiated by Murdoch and culminating with the rather baffling and patronising article by Mathers et al. ${ }^{2}$ Now we have had time to calm down we would like to put forward the case for practice-based primary care research, drawing on our experiences and those of our colleagues over the last 20 years.

The RCGP was very much at the forefront of establishing funding and support for GP researchers, and The Honiton Practice was one of the first RCGP Research Practices in the country being appointed in 1995. This gave the practice a sum of money to establish some research infrastructure with a view to starting research in the practice. Added to this Clare Seamark was awarded a RCGP Research Fellowship to undertake and complete a masters degree that was based solely in primary care.

Practice-based research has been a strong theme in the South West, particularly in Exeter and East Devon. There have been a number of research practices supported under NHS Research Funding schemes, such as Culyer. These schemes created a critical mass of GP researchers and associated research staff for remarkably little investment.

To our knowledge there have been at least five doctorates awarded to local GP researchers and many masters degrees.

Within the practice we know most about (Honiton), David Seamark already had a biochemical $\mathrm{PhD}$ before becoming a GP and starting in pragmatic practicebased research. Since then among the partners of the practice there have been two masters degrees and one doctorate (and one masters is ongoing). There have been 61 peer reviewed papers published in 22 journals ranging from the $B M J$ to Soc Sci Med and 15 of these papers have been in the BJGP.

We have been researching in fields as widely divergent as teenage sexual health to anticoagulant monitoring. We have had presentations at local, national, and international meetings. Many of our practice-initiated studies have led to significant changes in the way we and our PCT work. Work undertaken showing that anticoagulant monitoring and management by practice nurses was safe and reliable led to the roll-out of this service to the other practices in our PCT. Work on the benefits of pulmonary rehabilitation offered in community hospitals again led to the extension of this service to the rest of the PCT.

We published one of the first papers jointly authored by a patient, (BMJ) that attracted a lot of attention. We have also tried to encourage further patient involvement and have one study that was actually initiated by a patient from his own observations and a desire to know more and help doctors understand further people with chronic pain. He also became a member of the research team, undertook research training, and was an equal partner in the publications and presentations.

Our research experience and practical day-to-day knowledge of general practice has led to numerous collaborations (still ongoing) with academic departments in the UK, US, Australia, and India.

We have to move with the times and although our practice still continues to attract some research funding, as outlined in the correspondence, a lot of it is now linked to participating in larger studies and helping researchers access patients registered with the practice. We also try to move with these new ventures while still trying to hold onto what started us in research in the first place: the patients and clinical situations we meet each day and that stimulate more questions.

David Seamark is currently Research Champion for the local PCRN and we are both clinical leads for the new Academic Clinical Fellows in Primary Care based at the Peninsula School of Medicine and Dentistry.

The strength of general practice-based research is the generation of pertinent research questions, the piloting of ideas in preparation for substantive studies, and the translation of such research into evidence based practice.

David Seamark,

The Honiton Group Practice.

Clare Seamark,

The Honiton Group Practice,

Marlpits Lane EX14 2NY.

E-mail: cjseamark@doctors.org.uk

\section{REFERENCES}

1. Murdoch JC. The end of practice-based research? Br Gen Pract 2009; 59(558): 52.

2. Mathers N, Howe A, Field S. Clinical research by GPs in their own practices. Br J Gen Pract 2009; 59(561): 296-297.

DOI: 10.3399/bjgp09X454151

\section{Author's response}

The letter by Seamark and Seamark ${ }^{1}$ is typical of the response from practicebased researchers on this subject. Privately, I have received several letters with the same themes - pride in the quality and publication of practice-based research, and disappointment and frustration that these efforts have not 